\title{
Modeling the Periodicity of the Renewal of Production Assets in Manufacturing Enterprises
}

\author{
Zharikov Victor Danilovich ${ }^{1}$, Zharikov Valery Viktorovich ${ }^{2} \&$ Bezpalov Valery Vasilievich $^{3}$ \\ ${ }^{1}$ Tambov state technical university, Tambov, street Chichkanova, 18, k.37, Russian Federation \\ ${ }^{2}$ 107150, Moscow, street Losinoostrovskaya, 49, Russian Federation \\ ${ }^{3}$ Moscow State University of Economy, Statistics and Informatics, Moscow, Nezhinskaya St., 7, Russian \\ Federation \\ Correspondence: Zharikov Victor Danilovich, Tambov state technical university, 392008, Tambov, street \\ Chichkanova, 18, k.37, Russian Federation. E-mail: valerib1@yandex.ru
}

Received: July 15, 2014 Accepted: August 13, 2014 Online Published: November 27, 2014

doi:10.5539/ass.v10n24p28 URL: http://dx.doi.org/10.5539/ass.v10n24p28

\begin{abstract}
The article is solved a major problem for the industrial enterprises-define frequency of updating of Park of process equipment. It is proposed to simulate this process on the basis of change of volume of sales in comparison with volume of the profitability threshold, as well as by the ratio of the average costs and product sales and its market prices (without value added tax and excise taxes). The upgrade process equipment is within the relations of producers (in our case) polymer engineering and consumers, in particular, the state of basic production assets in the sectors of its use as technological equipment-casinobarrierejeux industry (tire, rubber, rubber footwear and other).
\end{abstract}

The proposed concept of the update includes several steps: the optimization of the Park of the process equipment depending on the structure of labor and production volumes, select the type of reproduction (reconstruction or technical re-equipment), as a rule, with the replacement of technologies, financial support.

The proposed algorithm and the software product to determine the periodicity of technical re-equipment and reconstruction of production, which can also determine the type of reproduction.

The renewal of production assets is a natural process of their aging. When technology and equipment are renewed, they are substituted for new resource-saving and more efficient ones. Renewal problems constantly interest Russian academic economists including V.D. Matsuta, G. Naydyonov, V.K. Faltsman, D.M. Palterovich, etc. Foreign scientists who in some measure solve renewal problems include J. Stiglitz, R. Waterman, S. Fisher, R. Dornbusch, R. Shmalenzi, J. Hicks, etc.

This problem is topical because production capabilities (technologies and facilities) become out of date very quickly due to innovations. For example, about $75 \%$ of manufacturing machinery in Russian polymeric machine-building enterprises is in use for more than 7 years (over the standard operation time and with normal depreciation for renewal equal to 15\%) (Gerasimov, 2009).

Russian and foreign scientists solved many problems connected with the renewal of production assets. However the questions of renewal periodicity are still not solved. It is still difficult to decide how deep technical renewal should be and how to model this process without subjective influence.

Modern concept for the renewal of production assets in manufacturing enterprises must include two phases (Zharikov, 2003), (Zharikov, 2013), (Zharikov, 2006), (Yershova, 2012):

1) Manufacturing machinery fleet is to be optimized due to the declining demand and consequently falling production output.

2) The periodicity of renewal stages should be forecasted.

3) Equipment renewal should be connected with the substitution of technologies along the whole processing flow. 
Keywords: updating, business assets, industrial enterprises, optimization of park of cars, modeling, forecasting of frequency of updating

\section{The Optimization of Manufacturing Machinery Fleet and the Acceleration of Its Renewal}

In recent years many facts (lack of financial resources and high borrowing costs) dropped the renewal of production assets and its particularly active part. Such a situation in manufacturing enterprises reduces the introduction of advanced technologies in manufacturing consumer goods and production facilities. Depreciated machinery fleet and outdated technologies increase manufacturing costs and lower the product quality (Aleksandrov, 1994). The competitive advantage of goods is determined first of all by their quality and price.

The proposed concept directs manufacturing enterprises towards a long-term prospect in solving the problems concerning the renewal of production capabilities. The effectiveness of the renewal is grounded by the theoretical study of trends in facility market. These trends show that, on the one hand, the stocks of machinery resources are running out, but on the other hand, the growth trends take shape because of the need to ensure the life of all components forming the economy of the country (Zharikov, 2001; 2003).

The concept allows deciding one of the main issues of the renewal process-the question of financial provision. Alongside with the internal funds of the participants, they borrow the funds of commercial banks, which serve the production spheres of economy, and also the credit funds from other sources.

In the developed concept, the authors give a method for the renewal of manufacturing capabilities. The main idea is in the adoption of new productive technologies and the renewal of manufacturing machinery fleet. As it was mentioned already, in the present historical period, which is very difficult in many aspects for manufacturers, we see a rapid drop in the intensity of production programs. This fact gives every enterprise a chance to decide on its strategic goals determining its main aspects of work: production output, specialization, the degree of cooperation, the circle of consumers and vendors, etc. In terms of these parameters, it is necessary to study the problems connected with the transition to a new level of machinery and technology that will improve the quality of products along with other components of production. This problem should be solved within the circle of consumers and vendors. For example, the plants of polymer machine-building should consider their tactics and strategy depending on and influenced by the development strategy of conjugate kinds of production specializing in rubber processing. In this case, it is necessary to take into account the competitive environment in border areas of the market. For polymeric machine-building, this market is plastic processing equipment which is identical to rubber processing equipment (extruders, injection machines, presses, granulators, etc.). Today, the market of plastic processing equipment in Russia is almost empty because $85 \%$ of the scientific and industrial potential of the USSR was left in Ukraine and the lifetime of the machinery fleet practically runs out. That is why there will be a big boom of demand on this market in recent future. Then the demand will become stably high (Zharikov, 2000; 1998).

The implementation of the proposed concept will make it possible to "revive" the process of renewal in manufacturing enterprises and to move to a higher technical level of production. In its turn, this will allow increasing the competitive status of Russian goods.

The mentioned points of the proposed concept are of system character. They are meant for a constant and long-term joint work of manufacturing enterprises.

The condition of the active machinery fleet-the growth rates, the specific weight of equipment in the structure of the main production assets, its age structure, the rates of retirement and renewal-has a great influence on the scale and structure of the demand for equipment (Birman, 1997).

If we consider the retirement of depreciated and outdated equipment in the active machinery fleet, we can conclude that the percentage of retirement is still quite low. The renewal of polymeric machinery also has a low percentage of retirement. At the same time the share of installed equipment is high, and if the all the installed equipment were sent to the replacement, the lifetime of equipment will be within the norm. However, generally, the equipment installed in the shops of rubber processing plants was sent to the expansion of the existing machinery fleet. Thus the retirement remained at a low level (Zharikov, 1997).

The comparative analyses of depreciation charges-the transfer value of machinery for the product (depreciation)-shows that they were enough to renew the depreciated machinery fleet. The retirement rate of the production assets is promoted by:

a) changes in the investment policy (the majority of capital investments will be directed to the technical re-equipment of active manufacturing enterprises); 
b) capital formation for production development and machinery supply. These measures will allow renewing production assets rapidly and at a higher technical level.

The proposed concept includes the methods for the renewal of manufacturing capabilities which is divided in two stages (Zharikov, 2000):

1) The optimization of the manufacturing machinery fleet. A part of equipment is not used in plants and the majority of it is depreciated because the demand for products reduced and changed. The retirement or sale of the depreciated machinery fleet will slightly improve the age structure of active production assets. Besides, it will decrease the tax burden (the reduction of property tax) and maintenance expenses.

The necessary machinery fleet $(\mathrm{W})$ can be found with a sufficient precision with the help of this formula:

$$
W=\frac{N_{i} \times t_{i j}}{T_{j} \times 100} \times K_{j} \times m
$$

where $\mathrm{N}_{\mathrm{i}}$ is an annual program for i product in schedule period, pcs.;

$\mathrm{t}_{\mathrm{ij}}$ is the labour content of $\mathrm{i}$ product in $\mathrm{j}$ operation, standard hour;

$\mathrm{T}_{\mathrm{j}}$ is a real annual working time of equipment in $\mathrm{j}$ operation, $\mathrm{h}$.;

$\mathrm{K}_{\mathrm{j}}$ is a labour content deviation coefficient in $\mathrm{j}$ operation. This coefficient helps to take into account the technologically necessary fleet of machinery because its size increases at the expense of changes in product mix and consequently in the structure of labour content;

$\mathrm{m}$ is the growth rate of manufacturing output in percents per basic year.

2) The determination of the extent of financing. First of all, if the financing is minimal, it is necessary to renew the equipment that allows introducing new technologies. The annual extent of financing (S) can be approximately found on the basis of the volume of active production assets and depreciation norm the following way:

$$
S=\frac{G \times(H+\varepsilon)}{100}, \varepsilon=\frac{Y_{i}}{t}
$$

$\mathrm{G}$ is the volume of active production assets, rub.;

$\mathrm{H}$ is the depreciation norm for a complete renewal of manufacturing machinery, \%;

$\varepsilon$ is the acceleration rate for the renewal of depreciated machinery, $\%$;

$\mathrm{Y}_{\mathrm{i}}$ is the specific weight of $\mathrm{i}$ equipment group liable to accelerated renewal in total volume of production assets, $\%$;

$\mathrm{t}$ is the schedule period for the catch-up with the backlog in manufacturing machinery renewal, years.

\section{Forecasting the Periodicity of Machinery Renewal}

The scientific-technical progress promotes the development of the need for machine-building products. This causes the diversification of machines, equipment and technologies used for their production. That is why the intensified work of machine-building enterprises in competitive environment is conditioned first of all by the flexibility of production (here flexibility means a rapid change of products with minimal additional resources) (Zharikov, 1999).

In the stable external environment of an enterprise it can be equipped by specialized facilities and staffed with personnel of narrow specialization. At that, the suppliers of raw stock, materials, semi-finished products and components may remain stable.

Market economy is not stable. The factors of instability include the prices for resources, changes in the tax policy of the country and deviations in demand and supply due to the insolvency or even bankruptcy of both consumers and suppliers.

The machine-building enterprises should be equipped with machinery which allows changing the product mix with minimal additional resources (universal equipment, flexible computer-aided manufacturing and adaptable control systems). Besides, they should be oriented towards wide specialization and highly-qualified workers (Meshkova, 2003).

The transition from narrow specialization to the wide one made enterprises need a frequent renewal of production assets: technology, equipment, outfit, tools, raw stock and materials. A special role in flexibility and 
the improvement of technical level of production belongs to the re-equipment and renewal of enterprises (Zharikov, 2004).

The periodicity of re-equipment and renewal is conditioned by the rates of physical depreciation and obsolescence of machinery, changes in product mix and applied technology (Fisher, 1993). The elongation of the cycle of re-equipment and renewal decreases capital costs. However, as this cycle is elongated, the costs for repair and maintenance increase.

The optimization of this process (choosing an effective cycle for re-equipment and renewal) consists, on the one hand, in the application of new machinery and new technologies in manufacturing new goods, and, on the other hand, in the minimization of additional costs (investments in innovations) and their profitability.

As a rule, an enterprise simultaneously produces different goods by different technologies which are, as well as the demand, at different lifetime stages. These circumstances and the competition appeared in the internal market of industrial commodities force an enterprise to provide the flexibility of production efficiently.

The duration of the re-equipment and renewal cycle is conditioned by the life cycle of demand, technology and product (Figure 1). If technology is stable, the life cycle of demand and product is long. A fruitful technology provides the long-term character of demand and technology. Product can change several times within the limits of one technology because the life cycle of product is much less than the life cycles of demand and technology. If technology is unsteady within the life cycle of demand, the life cycle of technology and product often change.

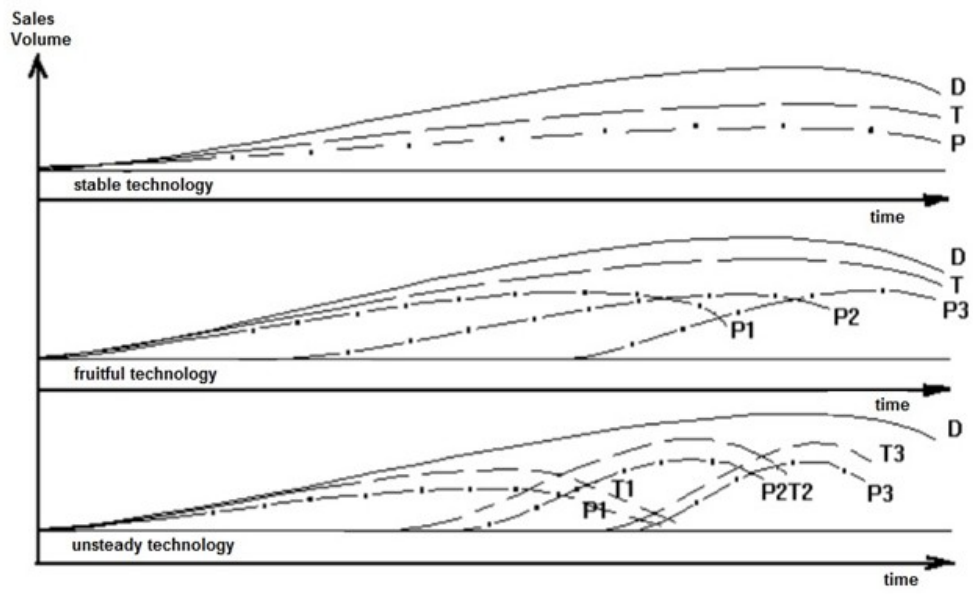

Figure 1. The life cycle of: demand-D; technology-T; products-P (Zharikov, 2002)

The diagram (Figure 2) shows the periodicity of renewal and re-equipment. Between these events, they conduct inspections and small, medium and big repair (repair costs).

The optimal duration of re-equipment cycle, which provides a flexible response to changes in market situation, can be found on the basis of:

- sales volume $O_{p}$, rub.;

- sales gain $\Delta O_{p}$, rub;

- the value of active production assets $F_{0} \times \alpha_{a}$ ( $\mathrm{F}_{0}$ is the residual value of production assets, rub.; $\alpha_{a}$ is the specific weight of active production assets);

- active production assets liable to a complete renewal $F_{0} \times \alpha_{a} \times \beta$ ( $\beta$ is a share of renewed equipment), rub.;

- the value of new equipment $\mathrm{K}$ (costs for renewal and reconstruction), rub.

$$
K=n \times S_{n}=F_{0} \times \alpha_{a} \times \beta \backslash S_{a v}
$$

( $\mathrm{S}_{\mathrm{n}}$ is a price of new equipment (machines, aggregates and lines), rub.; $\mathrm{S}_{\mathrm{av}}$ is an average residual value for a unit of depreciated equipment; $\mathrm{n}$ is the number of depreciated equipment liable to renewal); repair costs $F_{0} \times \alpha_{a} \times \gamma$ ( $\gamma$ is a value of repairs in turnaround intervals).

The periodicity of production assets renewal should be of the highest efficiency during the long periods of work, competitiveness and survival potential. In graphical form, it looks like this (Figure 2). 


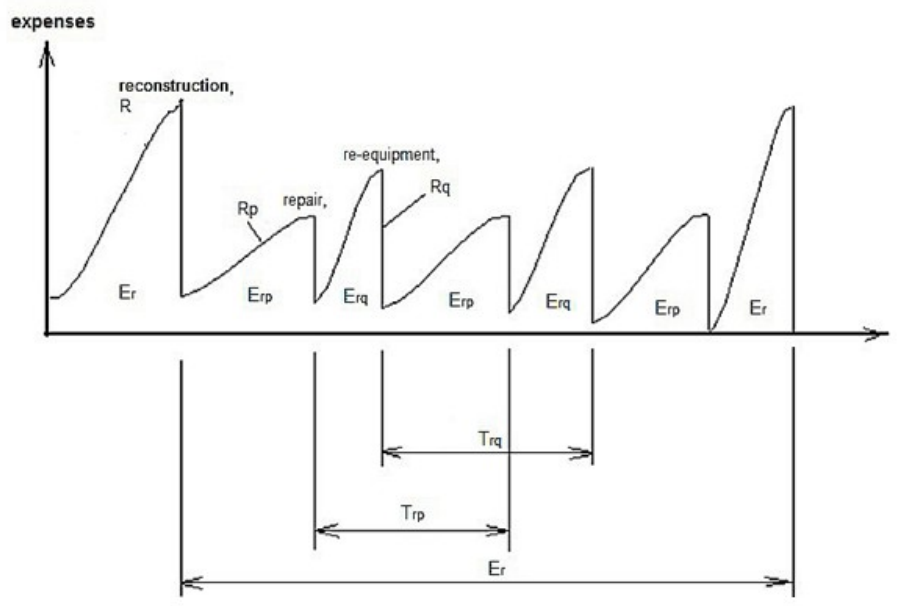

Figure 2. The periodicity of repair cycles, re-equipment and reconstruction of production (Pinedo, 2009)

If technology is stable, the cycle of reconstruction $T_{P}$ will obviously be equal to the cycle of demand $T_{D}$, i.e. $\mathrm{T}_{\mathrm{P}}=\mathrm{T}_{\mathrm{D}}$; and the cycle of re-equipment $\mathrm{T}_{\mathrm{tp}}$ will be determined by the cycle of physical depreciation and obsolescence of manufacturing machinery fleet $T_{n}$ i.e. $T_{t p}=T_{n}$.

If the cycle of demand is eternal (matches, bred, etc.), then $T_{P}=T_{n}$ or $T_{t p}=T_{n}$, i.e. in case of physical depreciation and obsolescence of machinery, there will be a reconstruction or re-equipment of production system.

If a fruitful technology is used in production, the duration of cycles can be found the following way:

$\mathrm{T}_{\mathrm{P}}=\mathrm{T}_{\mathrm{D}}=\mathrm{T}_{\mathrm{t}}$, and $\mathrm{T}_{\mathrm{tn}}=\mathrm{T}_{\mathrm{P}}$,

i.e. the duration of reconstruction cycle is equal to the cycle of demand and the cycle of applied technology $\mathrm{T}_{\mathrm{T}}$, and the cycle of re-equipment is equal to the lifetime of product.

If the production system is based on the changing technology, then $T_{P}=T_{D}$, and $T_{t p}=T_{t}=T_{P}=T_{n}$, then reconstruction cycle is equal to the standard lifetime of equipment.

$T_{t}=T_{n}$, and $T_{n}=100 / H_{a}$, where $H_{a}$ is depreciation norm for renewal, $\%$.

The optimal periods of reconstruction and re-equipment were found by the sales changes: at start time $t_{0}$ we find minimal sales volume $\mathrm{Q}_{\mathrm{o}}$, which covers all expenses (the breakeven point). Then the sales volume decreases, that is $\Delta Q$ has a stable negative trend. This fact notifies that there is a need for re-equipment or reconstruction. A constant intensive sales increase calls for the expansion of manufacturing capabilities.

In the analysis of sales volume dynamics, there are two possible alternatives. The first one is when the sales volume is much higher than the breakeven point, and in this case only the replacement of depreciated and outdated odd equipment will require capital financing. The second one is when there is a constant decrease of sales volume and it approaches the breakeven point. In this case measures are necessary for the renewal or modernization of products. Usually this requires new technologies and consequently the re-equipment or reconstruction. The breakeven point $\mathrm{E}$ is found by the formula:

$$
E=B / Z_{\text {nam }}=B /(S-V), p c s
$$

where $B$ is constant costs of an enterprise in business period, rub.

$\mathrm{S}$ is the price of products (VAT and excise duties excluded), rub.

$\mathrm{V}$ the volume of variable costs in product price, rub.

In calculating the cycles of re-equipment and reconstruction, we also took into account the costs for manufacturing and marketing, and also the structure of costs.

Total (gross) manufacturing and marketing costs are found by:

$$
T C=F C+V C
$$

where $\mathrm{FC}$ is constant costs ;

$\mathrm{VC}$ is variable costs. 
In its turn:

$$
F C=F C_{0}+F_{0} \times \alpha \times \gamma
$$

where FCo is constant staff costs, land tax, etc.;

$\mathrm{F}_{\mathrm{o}}, \alpha, \gamma$ are the costs for the repair and rebuilding of equipment;

$\mathrm{F}_{\mathrm{o}}$ is the residual value of production assets;

$\alpha_{0}$ is the specific weight of active production assets;

$\gamma$ is the value of repair in turnaround interval per one ruble of the value of active production assets.

Average costs AS:

$$
A S=T C / Q, \text { then } Q=T C / A S
$$

Product price $\mathrm{S}$ is formed by average costs and profit $\mathrm{P}$. That is $\mathrm{S}=\mathrm{AC}+\mathrm{P}$.

When costs completely force the profit out of the price, that is $\mathrm{P}=0$, and $\mathrm{S}=\mathrm{AC}$, then such product should be laid off and the re-equipment or reconstruction should be performed.

After a re-equipment (reconstruction), average costs become minimal because of low repair costs (equipment is new), and the sales volume can grow due to lower prices and higher quality of goods (Bezpalov, 2012).

In time, average costs grow on because the increase of repair costs, the profit comes down (with the same price), and the sales volume drops because of market saturation. Then the need for re-equipment appears (Bezpalov, 2013).

After repeated re-equipment, a moment can come when the reduction of average costs only by re-equipment fails. In this case, it is necessary to perform a deep reconstruction with the renewal of technology and products (Bezpalov, 2014).

An algorithm and a program were developed in order to find out the periodicity of re-equipment and reconstruction in manufacturing system. They allow identifying the moment of production assets renewal.

The program work the following way. After the data request, the program moves to the main cycle $\left(i>k_{o l}, i=\right.$ $1 \ldots \mathrm{k}_{\mathrm{ol}}$ ) in which it checks each kind of products.

If the output of a product is lower than the breakeven point (the sales volume covers the constant and variable costs of the enterprise), we can see the following:

- the required variables and counters are zeroed;

- a message is displayed;

- the sales volume is calculated $\left(\mathrm{Q}_{1}\right)$;

- the denominator of the mathematical model is calculated in order to find the breakeven point $\left(Z_{\text {nam }}\right)$;

- the breakeven point is found;

- the values of $Q$ and $E$ are calculated;

- condition $\mathrm{Q}_{1} \geq \mathrm{Q}_{1}$-old is checked (the sales volume decreases or grows);

If the sales volume grows or is equal at the previous stage of calculation, then $t$ increases and there is a move back to calculating $Q$ with other $t$ value.

If $\mathrm{Q}$ decreases to $\mathrm{Q}<\mathrm{E}$, then a message about the necessity of re-equipment is displayed. Then we increase $\mathrm{t}$ (the re-equipment was performed). The indexes change, and we calculate $\mathrm{Q}$ with a new value of $t$. If in this case $\mathrm{Q}<$ $\mathrm{E}$, then we see a message about reconstruction. By increasing I, we move to calculating the next kind of products.

If $\mathrm{i}>\mathrm{kol}$, the program moves to the end.

The developed mathematical model and the computer program make it possible to find an optimal cycle for the renewal of products, technology and production system.

\section{Conclusion}

The renewal of manufacturing equipment is conditioned by its aging and new technologies appearing in consuming sectors. At the same time, the premature renewal leads to additional capital investments, and the late renewal causes machinery aging and the growth of current maintenance costs leading to the decrease of product competitiveness (high costs). That is why the process of renewal should be optimized. 
First of all, it is necessary to renew the fleet of manufacturing machinery depending on the production output and the structure of labour content. Then one should determine the periodicity and reproduction type (re-equipment or reconstruction).

Using a scientific approach to the problem of renewal, the authors proposed an algorithm and a computer program for the calculation of periodicity and reproduction type which can help to optimize this process.

\section{References}

Aleksandrov, G., \& Pavlov, A. (1994). The Renewal of the Main Production Assets. Intensification, efficiency, stimulation. Moscow: Economica.

Bezpalov, V. (2012). The Structural and Functional Model for the restructuring of Production Management. The Review of the RANS, 2(12), 12-16.

Bezpalov, V. (2013). A Complex Approach in Building a Production Management System. Innovations and Investment, 2, $15-18$.

Bezpalov, V. V. (2014). The Design of Restructuration Mechanism for a Production Management system. The Topical Problems of Management, 8-12.

Birman, G., \& Schmidt, S. (1997). The Economic Analysis of Investment Projects. Moscow: Banks and Exchanges.

Fisher, S., Dornbusch, R., \& Shmalenzi, R. (1993). Economics. Moscow: Delo.

Gerasimov, B. (2009). Planning for Enterprises. Tutorial. Moscow: FORUM.

Ivert, L. (2009). Advanced planning and scheduling systems in manufacturing planning and control processes. (ISSN 1654-9732 Licentiate thesis Report number L2009:036, Division of Logistics and Transportation Department of Technology Management and Economics Chalmers University of Technology, SE-412 96 Göteborg, Sweden, Printed by Chalmers Reproservice Göteborg).

Meshkova, L. (2003). Planning and Forecasting in Industry. Tutorial. Tambov.

Pinedo, M. (2009). Planning and Scheduling in Manufacturing and Services, Springer Science + Business Media. LLC.

Yershova, M. (2012). The Rules of Quality and Adaptation. Tambov: Chesnokova P.

Zharikov, V., \& Zharikov, V. (2002). The Methodology for the Development of Business Processes in Rubber and Asbestos Manufacturing Plants. Moscow: Mashinostroenie-1.

Zharikov, V. (1997). The Condition and Technical Improvement of Polymeric Machinery in Rubber Processing Industry. Moscow.

Zharikov, V. (1998). The Theory and Methodology for the Study of Facilities Market. Tambov: the TSTU.

Zharikov, V. (1999). Economic Relations in Manufacturing Enterprises in Forming Market of Facilities. Tambov: the TSTU.

Zharikov, V. (2000a). The Problems of Facilities Reproduction in Manufacturing Enterprises in Forming Market. Moscow: Machinostroenie.

Zharikov, V. (2000b). The Theory and Methodology for the Reproduction of Facilities in Manufacturing Enterprises. Synopsis of Thesis. Voronezh.

Zharikov, V. (2001). Resource Saving in Metal-Working Industry. Production Manager. Voronezh: the VSU.

Zharikov, V. (2003a). Economic Problems in Production Management. Production Manager. Economics and Finances, 4(19), 55-59. Moscow.

Zharikov, V. (2003b). The Influence of Inflation on the Results of Production. Production Manager. Voronezh: the VSU.

Zharikov, V. (2004). The Forecasting of the Need of Enterprises for Equipment. Moscow: Economica.

Zharikov, V. (2006). The Improvement of Quality in Machine-Building Industry: Reserves and Mechanisms. Tambov: The TSTU, 2(12), 68.

Zharikov, V. (2013). The Principles and Approaches for Cluster Economy in Machine-Building Industry. Lugansk: The Dal'University, 4, 20-25.

\section{Copyrights}

Copyright for this article is retained by the author(s), with first publication rights granted to the journal.

This is an open-access article distributed under the terms and conditions of the Creative Commons Attribution license (http://creativecommons.org/licenses/by/3.0/). 